\title{
MIGRACIONES FORZOSAS, NUEVOS REFUGIOS Y DERECHOS HUMANOS
}

\author{
Cristina Gortázar Rotaeche \\ Universidad Pontificia Comillas de Madrid, Facultad de Derecho \\ Cátedra Jean Monnet en Derecho de la Unión Europea
}

\begin{abstract}
The article at hand attempts to string together a reflection on the awkward limits concerning the concepts of economic immigration, new refugees (persons warranting international protection who do not fall under the out-dated demands of the Geneva Convention on Refugees) and refugees protected by this Convention. The obvious reason that International Law covers refugee status and rarely does so regarding cases of economic immigration is that, historically, International Law has dictated that migratory movements respond to more or less voluntary motives, while the term refugee implies that a person has no possibility for protection in his or her State of origin. However, in present-day International Law, we find a lack of precision: Are migrations from the Third World voluntary? If the answer is no, which cases are voluntary and which are not? Or perhaps, are only those migration provoked by the State of origin to be considered involuntary ?.Then, how to consider human migrations caused by natural disasters?

Finally, the answer of States to forced migration and the protection of «new refugees" brings with it a coherent response vis-à-vis cultural diversity, since this will be a determining factor in the so-called «integration" of the immigrants and refugees. Moreover, any reflexion on the peaceful co-existence of different cultures leads us to the never-ending debate on the origin of fundamental human rights and their universal nature.
\end{abstract}

KEY WORDS Economic migration, refugees, human rights, cultural diversity, social integration
RESUMEN El presente artículo intenta hilvanar una reflexión sobre los escurridizos límites entre los conceptos de inmigración económica, nuevos refugiados (personas dignas de protección internacional que no responden a las rancias exigencias del Convenio de Ginebra sobre refugiados) y refugiados amparados por dicho Convenio. La razón prístina para que el Derecho internacional se ocupe de los supuestos de refugio y apenas lo haga con respecto a los casos de inmigración económica está en que, desde antiguo, este Derecho ha entendido que los movimientos migratorios obedecen a motivaciones más o menos voluntarias, mientras que el refugio implica que una persona se encuentra sin posibilidad de protección en su Estado de origen. Sin embargo, en el Derecho internacional contemporáneo nos encontramos ante un cuadro dominado por la imprecisión: ¿Son voluntarias las migraciones provenientes desde el tercer mundo? En caso de respuesta negativa, ¿cuáles son forzosas y cuáles no lo son? ¿Acaso sólo son involuntarias las provocadas por el Estado de origen, sea por acción u omisión? ¿Qué sucede entonces con los desplazamientos humanos que traen causa en las catástrofes naturales?. Por fin, la respuesta de los Estados ante las migraciones forzosas y la protección de los nuevos refugiados trae consigo una toma de postura coherente ante la diversidad cultural, ya que ésta será determinante para que la denominada "integración" de los inmigrantes y refugiados. Asimismo, cualquier reflexión sobre la convivencia entre distintas culturas nos conduce al perdurable debate sobre el origen de los derechos humanos fundamentales y de su carácter universal, inderogable e indivisible.

PALABRAS CLAVE Migración económica, refugiados, derechos humanos, diversida cultural, integración social.

\section{Las migraciones forzosas}

Los diferentes estudios llevados a cabo por Naciones Unidas y la OCDE no vacilan en vaticinar que los movimientos migratorios forzosos de los paises en desarrollo hacia los paises desarrollados van a seguir aumentando en las próximas décadas. Varias son las tareas que la comunidad internacional ha de asumir a ese respecto.
En primer lugar, a los paises receptores nos corresponde colaborar decididamente a que los movimientos previstos aminoren, lo que se logrará potenciando las economías de los paises emergentes para que puedan salir de su pobreza. La principal manera de hacerlo consiste en liberalizar el comercio de sus productos en nuestros mercados. Recordemos con Lamo De Espinosa que la ayuda al desarrollo, incluso si alcanza el $0^{\prime} 7 \%$ del PIB, no pasa de ser «un alivio 
para nuestras propias conciencias: "trade not aid", claman los países pobres y deberíamos escucharlos más que dedicarnos a pensar por ellosin (Lamo De Espinosa, 2004, 136) ${ }^{1}$. La anterior referencia a inducir la disminución de los movimientos migratorios forzosos poniendo el énfasis en el factor económico ${ }^{2}$ podría parecer algo simplista, sin embargo, es preciso tener en cuenta que, aunque no todos los movimientos migratorios forzosos traen causa en la pobreza, cabe afirmar que los desplazamientos causados por la guerra, la violencia, y las violaciones flagrantes de los derechos humanos, así como los provocados por las catástrofes naturales, tienen una clara relación con la debilidad de las economias de los paises donde estas situaciones se producen.

En segundo lugar, los paises de acogida deben adoptar las normativas jurídicas pertinentes para que quienes lleguen lo hagan de una manera razonable y dentro de la legalidad. Esta será la conditio sine qua non para que los inmigrantes puedan comenzar su proceso de integración en las sociedades receptoras. Cuando en dichas sociedades se menciona el "efecto llamada" que provocan, por ejemplo, los procesos extraordinarios de regularización de inmigrantes -como el que se vive estos meses en España-, parece quedar en un premeditado olvido que el verdadero "efecto llamada" lo produce la existencia de puestos de trabajo por cubrir.
Asi, una vez que los gobiernos de los países receptores de inmigración toman conciencia de que existe empleo en sectores que no suelen atraer a los nacionales, deberian arbitrar los mecanismos para importar la mano de obra extranjera de manera legal. El nuevo Reglamento de Extranjería en España da un tímido paso en este sentido al crear, por ejemplo, los visados para búsqueda de empleo. Quizá este sea el comienzo de un nuevo enfoque en materia de migración económica que termine con esa máquina de producción de trabajadores extranjeros en situación irregular en que han convertido a determinados paises receptores -este es, desgraciadamente, el supuesto de España (Gortázar, 2002, 2-3)- ciertas normas de extranjeria y las prácticas a las que éstas han dado lugar.

Otra labor de calado en lo que respecta a las sociedades de acogida consiste en la sensibilización de la opinión pública y la ruptura con falsos lugares comunes. Hace algunos años, el Instituto Universitario de Estudios sobre Migraciones de la Universidad Pontificia Comillas realizó y publicó una investigación, encargada por el Ministerio de Trabajo y Asuntos Sociales, en la que estudiaba la relación entre la inmigración y la economía española; los resultados fueron concluyentes y casi llamativos en cuanto la aportación que la inmigración realiza al Tesoro Público (Aparicio, R. y Tornos, A., 2002) Los medios de comunicación, muchas de las veces, no contribuyen a dibujar correctamente the big picture. Nos muestran sólo la cara menos amable del fenómeno migratorio, fomentando con ello la creación, en la opinión pública menos ilustrada, de una relación directa entre inseguridad y normativas sobre inmigración - precisamente, respecto de las que, de entre ellas, son más respetuosas con los derechos humanos fundamentales-, así como la falsa impresión de que los inmigrantes producen una verdadera sangria económica y social ${ }^{3}$, produciendo un importante gasto a nuestra sanidad pública, ocupando -los hijos y nietos de inmigrantes- los puestos en nuestras escuelas, lo que provoca el retraso escolar de los niños autóctonos al ralentizar el ritmo de la clase la incorporación de menores con peor conocimiento de la lengua del país receptor, etc.

Al respecto, resulta -cuando menos- sugerente el experimento mental que realiza Merle $(2002,45-57)$. Compara la situación actual, en la que la inmigración del tercer mundo está limitada por las normativas de los paises industrializados pero existen prestaciones sociales aseguradas para cualquier inmigrante, con una situación imaginaria, en la cual la inmigración hacia el primer mundo se permitiría sin ningún tipo de restricción pero en la que no se daría ninguna prestación social o asistencial para las que no se hubiera cotizado previamente. En este supuesto imaginario, el candidato solo podría inmigrar cuando tuviera asegurado un puesto de trabajo y sólo permanecería mientras lo conservara, permitiéndosele una breve estancia como buscador de empleo. Como este "derecho a la inmigración» empeoraria a los trabajadores nacionales, Merle propone que el Estado prevea una compensación de esta pérdida mediante una subvención financiera de puestos de trabajo y un subsidio de desempleo para los nacionales y los antiguos inmigrantes que se vieran afectados por esa competencia adicional; estas medidas serian financiadas por los propios inmigrantes. En suma: los inmigrantes serian siempre contribuyentes netos. Concluye MERLE que, contrariamente a la opinión predominante, el candidato de su experimento imaginario saldría beneficiado en este modelo de "laboratorio" con respecto a su situación en el modelo actual Sin embargo, para dicho autor, la prohibición de inmigrar -o su regulación estricta- constituye la solución cómoda que elimina un dilema ético: Si el derecho a la inmigración existiera y se pudiera seguir apelando al principio de la diferencia, quedaría más evidente el contraste entre el bienestar propio (a la vez que

ARBOR CLXXXI 713 MAYO-JUNIO [2005] 133-142 ISSN: 0210-1963 
se mantiene el estatuto del meteco) y la conciencia (que se inclinaria por la eliminación de dicho estatuto de meteco).

Por otra parte, hay que ser plenamente conscientes de que las reacciones de xenofobia se producen casi siempre con respecto de la inmigración inadaptada: cuando la población inmigrante vive en guetos y se encuentra empleada precariamente en la economía sumergida es cuando se desencadenan los fenómenos de rechazo. Es decir, dichas respuestas adversas las provoca en mucha mayor manera la pobreza que el diferente origen racial 0 , incluso, las diferentes costumbres. Además, los fenómenos racistas y xenófobos tienen lugar, en buena medida, porque nos fijamos mucho más en aquello que el inmigrante tiene de distinto y no en lo mucho que tiene en común con nosotros: sentimientos, amor por los hijos, apego a la vida, necesidad de ser valorados, de ser queridos, etc.

Cabe terminar esta breve introducción estableciendo que los movimientos migratorios hacia los paises desarrollados son inevitables a corto y medio plazo, y -a la vez-, cuando dichos flujos se gestionan sabiamente, constituyen un importante beneficio para las sociedades de acogida. Sin embargo, ¿benefician también a los inmigrantes? ¿Y a las sociedades de origen de los mismos? (Gortázar, 2005) Los beneficios para los inmigrantes son discutibles: indudablemente, el acceso al primer mundo les resuelve el problema vital de hallar unas condiciones de vida digna para ellos y sus allegados más inmediatos, no obstante, es mucho lo que "se dejan" en el camino ya que el proceso denominado "de integración» ${ }^{4}$ es dificil -cuando no penoso- y los requisitos legales para acceder, por ejemplo, a la reagrupación familiar en los paises de recepción son costosos y, en ocasiones, irrespetuosos con el Derecho internacional de los derechos humanos ${ }^{5}$. Por lo que se refiere a las sociedades de origen, es preciso recordar que, junto a las ventajas económicas evidentes que producen las remesas de dinero enviadas por los inmigrantes, se producen ciertos efectos negativos de indudable relevancia, entre ellos, la llamada "fuga de cerebros", toda vez que no son inusuales los flujos de migración cualificada proveniente de paises en desarrollo hacia paises industrializados.

\section{Los nuevos refugiados}

Es evidente que puede y debe distinguirse entre los inmigrantes por razones económicas y los solicitantes de asilo o de protección humanitaria. La inmigración económica está fundamentalmente -aunque no exclusivamenteregulada por normas juridicas de origen interno, mientras que los supuestos de asilo o asimilables están reglamentados por el Derecho internacional público.

La razón pristina para que el Derecho internacional se ocupe de los supuestos de asilo y apenas lo haga con respecto a los casos de inmigración meramente económica está en que, desde antiguo, se ha entendido que los movimientos migratorios obedecen a motivaciones más o menos voluntarias, mientras que en los casos de asilo la persona se encuentra sin posibilidad de protección en el Estado de origen y por eso solicita protección fuera de él 6 .

Sin embargo, en el Derecho internacional contemporáneo nos encontramos ante un cuadro difuso, dominado por la imprecisión: ¿Son voluntarias las migraciones provenientes desde el tercer mundo? En caso de respuesta negativa, ¿cuáles son forzosas y cuáles no lo son? ¿Acaso son sólo involuntarias las provocadas por el Estado de origen, sea por acción u omisión? ¿Qué sucede entonces con los desplazamientos humanos que traen causa en las catástrofes naturales?

En mi opinión, sólo resultaría adecuado distinguir -otorgando tratamiento jurídico del todo independiente- entre los supuestos de inmigración y asilo si, de una parte, la inmigración no fuera realmente "forzosa" y, de otra, la protección internacional cubriera de manera efectiva todas las situaciones en las que la persona humana se encontrara desvalida y sin posible protección por parte del Estado de su nacionalidad o residencia habitual (para los supuestos de apatrídia)

Por lo que se refiere a los supuestos de asilo (a los refugiados) es preciso tener en cuenta que una gran parte de los Estados miembros de la comunidad internacional están vinculados por la Convención de las Naciones Unidas de 1951 sobre el Estatuto del Refugiado7, la cual contiene una definición de refugiado que claramente responde a las necesidades de protección internacional que provocó la segunda guerra mundial y el comienzo de la guerra fría. El Derecho internacional de los Derechos Humanos no ha logrado un texto de alcance "universal" más adecuado a las circunstancias que desde hace ya décadas definen a los que hemos venido en llamar nuevos refugiados ${ }^{8}$. Las interpretaciones que los jueces nacionales han realizado de la definición de refugiado contenida en la Convención de Ginebra han sido discrepantes y en ninguna ocasión los Estados han recurrido al Tribunal Internacional de Justicia 
para solicitar una interpretación definitiva según el Derecho internacional público.

Lo anterior ha motivado que proliferen distintos estatutos regionales ${ }^{9}$ para regular diferentes situaciones que resultan dignas de protección internacional y no se encuentran, a pesar de ello, entre los supuestos recogidos por la Convención de Ginebra. Las hambrunas, las catástrofes naturales $y$, especialmente, los conflictos armados o, más en general, las violaciones generalizadas de los derechos humanos, hacen que muy pocas personas desplazadas puedan vestirse con el estrecho traje que en 1951 se cosió para proteger a aquellos refugiados.

En cuanto a la realidad jurídica internacional vigente, ¿qué diferencia existe entre la protección que otorga a los refugiados la Convención de Ginebra y el resto de las protecciones jurídicas, mas en particular, la que en la Unión Europea se ha denominado Protección Subsidiaria?

Como avanzábamos, en 1951 se adoptaba en el seno de las Naciones Unidas la Convención de Ginebra sobre el Estatuto del Refugiado, la cual recoge la primera y única definición del término refugiado de carácter general y ámbito universal ${ }^{10}$. Su artículo primero se refiere al refugiado como la persona que "...debido a fundados temores de ser perseguida por motivos de raza, religión, nacionalidad, pertenencia a determinado grupo social u opiniones políticas, se encuentre fuera del pais de su nacionalidad y no pueda o, a causa de dichos temores, no quiera acogerse a la protección de tal país; o que, careciendo de nacionalidad y hallándose, a consecuencia de tales acontecimientos, fuera del país donde antes tuviera su residencia habitual, no pueda o, a causa de dichos temores, no quiera regresar a éln.

La Convención de Ginebra protege, por tanto, a los extranjeros 0 apátridas que poseen un temor fundado de sufrir persecución en su pais de origen o residencia habitual (en el caso de los apátridas) sólo cuando dicho temor fundado tenga un nexo con la raza, la religión, la nacionalidad, la pertenencia a un grupo social o las opiniones politicas y que como consecuencia de todo ello, soliciten protección no habiendo incurrido en ninguna de las cláusulas de cesación o exclusión previstas ${ }^{11}$.

Dos son las cuestiones que quizá han dado lugar a mayor controversia en cuanto a la interpretación de la definición de refugiado contenida en la Convención de Ginebra. Por una parte, el agente que provoca el temor fundado de persecución. ¿La protección se refiere sólo a persecución proveniente de un agente oficial del Estado? ¿También se extiende a los supuestos en los que el causante de dicho temor fundado de persecución sea un representante de facto del Estado? ¿Y si su origen es ajeno al Estado pero éste tolera dicha persecución? Por fin, ¿se han de entender incluidos los supuestos en los que la persecución está provocada por grupos o personas particulares y el Estado no las tolera, pero es incapaz de contraatacar y ofrecer la protección adecuada?.

Los especialistas en la materia hemos entendido que se encuentran incluidos todos estos supuestos -y la razón evidente es que la Convención de Ginebra no nace para castigar a los Estados que persiguen injustamente a sus ciudadanos, sino para proteger a los individuos desvalidos-, no obstante, la jurisprudencia estatal no siempre ha compartido esta tesis. Como máximo exponente de estas discrepancias, la Cámara de los Lores del Reino Unido llegó a entender que Francia y Alemania no debian ser considerados upaises seguros" en cuanto a las garantías respecto a la no devolución al país de persecución, precisamente, por no incluir la persecución proveniente de agentes no estatales dentro de la protección otorgada por la Convención de Ginebra ${ }^{12}$.

Por otra parte, la «pertenencia a un grupo social determinadow ha dado lugar también a diferentes posturas en la jurisprudencia y entre la doctrina científica. En muchas ocasiones se ha utilizado para cubrir determinados casos que no encajan en ninguno de los otros cuatro supuestos; son ejemplos conocidos los de temor de persecución por razón del sexo o por orientación sexual minoritaria. Sin embargo, esta interpretación tampoco ha sido pacífica.

En todo caso, aún para quienes hemos entendido que la Convención de Ginebra cubre supuestos de persecución proveniente de agentes no estatales y hemos considerado que la persecución por razón de genero u orientación sexual se encuentran amparadas por la protección de la Convención de Ginebra, resultaba evidente que la Convención de Ginebra no recoge muchos de los supuestos en los que se encuentran los nuevos refugiados. Esto es, aquellas personas que huyen de las consecuencias de las guerras o de otras violaciones flagrantes de los derechos humanos más fundamentales, así como supuestos de temor fundado a la sufrir la pena capital o de ser sometido a tortura u otros tratos o penas inhumanas o degradantes.

ARBOR CLXXXI 713 MAYO-JUNIO [2005] 133-142 ISSN: 0210-1963 
Es decir: la Convención de Ginebra no incluye importantes supuestos que, no siendo habituales en la época de adopción de la misma, son en la actualidad indiscutiblemente dignos de recibir protección internacional.

Mientras que, otros convenios de ámbito regional posteriores al texto ginebrino han sabido recoger definiciones de refugiado más adaptadas a las circunstancias actuales del fenómeno del refugio ${ }^{13}$, la respuesta de los Estados europeos ante los denominados nuevos refugiados no ha sido unívoca. No obstante, el Convenio Europeo de Derechos Humanos de 1950 (Consejo de Europa) ha servido de minimo común denominador ya que, aún no recogiendo el derecho de asilo en su articulado, contiene disposiciones que han sido utilizadas para la defensa de ciertos derechos de los solicitantes de asilo y los refugiados. Así, el Tribunal Europeo de Derechos Humanos (Tribunal de Estrasburgo) ha desarrollado una importante jurisprudencia (Chueca Sancho, 1998) ${ }^{14}$ al respecto, la cual ha tenido como consecuencia que, al comenzar las instituciones de la Unión Europea a discutir un concepto de Protección Subsidiaria que fuera capaz de superar la obsolescencia de la Convención de Ginebra, la jurisprudencia del citado Tribunal de Estrasburgo ha tenido un importante protagonismo.

Efectivamente, la protección de los nuevos refugiados en el seno de la Unión Europea comienza un importante proceso de armonización cuando en 1999 el Tratado de Amsterdam entra en vigor y añade al Tratado constitutivo de la Comunidad Europea un nuevo Título sobre "Visados, asilo, inmigración y otras políticas relacionadas con la libre circulación de personasi.

A partir de entonces empieza en el seno de las instituciones comunitarias la gestación de una prolija ristra de normas mínimas comunes sobre inmigración y asilo, fundamentalmente Reglamentos y Directivas. En el caso de las normas mínimas sobre asilo, el mismo texto del Tratado de la Comunida Europea, enfatiza que se adoptaran "con arreglo a la Convención de Ginebra y a su Protocolo Adicional, asi como a otros tratados pertinentesi.

De entre todos los Reglamentos y Directivas adoptados en virtud del Titulo IV del Tratado CE en los últimos cinco años relativas al asilo, la norma más relevante es, precisamente, la "Directiva del Consejo por la que se establecen normas mínimas sobre los requisitos y el estatuto al que pueden optar los ciudadanos de paises terceros y personas apátridas para ser refugiados o beneficiarios de otro tipo de protección internacionaln 15 .

Es decir, las instituciones comunitarias han decidido tratar en una misma Directiva el concepto de refugiado según la Convención de Ginebra y el nuevo concepto de Protección Subsidiaria a otorgar en supuestos que, no quedando dentro del ámbito de aplicación de la Convención de Ginebra, precisan, no obstante, de protección internacional.

La Directiva está en vigor desde el 20 de octubre de 2004 y el período de transposición para que los Estados Parte adopten las disposiciones legales, reglamentarias y administrativas para dar cumplimiento a la misma alcanzará hasta el 10 de octubre de 2006. El Reino Unido e Irlanda han notificado su deseo de participar en la adopción y aplicación de la Directiva; Dinamarca, por el contrario, no participara en la adopción de la misma no quedando, por ello, sujeta a su aplicación ${ }^{16}$

La Directiva reproduce la definición de refugiado de la Convención de Ginebra. En cuanto a las personas con derecho a Protección Subsidiaria, recoge la siguiente definición: "Nacional de un tercer país o apátrida que no reúne los requisitos para ser refugiado, pero respecto del cual se den motivos fundados para creer que, si regresase a su país de origen 0 , en el caso de un apátrida al país de su anterior residencia habitual, se enfrentaría a un riesgo real de sufrir alguno de los daños graves definidos en el artículo 15, y al que no se aplican los apartados 1 y 2 del artículo 17, y que no puede o, a causa de dicho riesgo no quiere acogerse a la protección de tal país».

Mientras que respecto del refugiado la expresión utilizada por la Convención de Ginebra y por la nueva Directiva comunitaria es la persona que "debido a temores fundados de ser perseguidon debido a su "raza, religión, nacionalidad, pertenencia a grupo social u opiniones políticas ${ }^{17}$ - la protección subsidiaria se refiere a aquella persona "respecto de la cual se den motivos fundados para creer (...) se enfrentaría a un riesgo real de sufrir alguno de los (siguientes) daños graves: "a la condena a la pena de muerte o su ejecución, o b)la tortura o las penas y tratos inhumanos o degradantes de un solicitante en su pais de origen, o c) las amenazas graves o individuales contra la vida o la integridad física de un civil motivadas por una violencia indiscriminada en situaciones de conflicto armado internacional o interno" ${ }^{18}$

ARBOR CLXXXI 713 MAYO-JUNIO [2005] 133-142 ISSN: 0210-1963 
En cuanto a las diferentes interpretaciones que en Europa se han llevado a cabo respecto del ámbito de aplicación de la Convención de Ginebra, la Directiva realiza una importante aportación. Aclara quienes son agentes de persecución ${ }^{19}$; define en qué consisten los actos de persecución 20 y explica cada uno de los cinco motivos de persecución ${ }^{21}$. Por ello, ya no cabe duda que serán considerados agentes de persecución (o causantes de daños graves, para los supuestos de protección subsidiaria) los agentes no estatales si puede demostrarse que el Estado o los partidos u organizaciones que controlan el Estado -incluidas las organizaciones internacionales- no quieren o no pueden proporcionar la protección contra la persecución (o los daños graves sufridos para los supuestos de protección subsidiaria).

Por otra parte, en relación con los motivos de persecución, la Directiva especifica en qué consiste la pertenencia a determinado grupo social, entre otras aclaraciones en una disposición se menciona:

"En función de las circunstancias imperantes en el país
de origen, podría incluirse en el concepto de determi-
nado un grupo basado en una característica común de
orientación sexual. No podrá entenderse la orientación
sexual en un sentido que comporte actos considerados
delictivos por la legislación nacional de los Estados
miembros. Podrán tenerse en cuenta aspectos relacio-
nados con le sexo de las personas sin que ellos por sí
solos puedan dar lugar a la presunción de aplicabili-
dad del presente artículo» 22 .

A pesar del indudable avance que supone la regulación de buena parte de los nuevos refugiados a través de la figura de la Protección Subsidiaria en la Unión Europea, hemos de poner el acento en que nos hallamos ante una solución parcial y con efectos sólo para un pequeño puñado de Estados en una región del mundo ${ }^{23}$. Las soluciones adoptadas en otras zonas del la tierra, en ocasiones son satisfactorias sólo sobre el papel ya que la situación fáctica en la que vive la región no permite su eficacia (i.e.: Convención de Addis Abeba).

En todo caso, es preciso concluir que las fronteras entre los supuestos de refugio y las nuevas formas de protección no están bien definidas. Carlier ${ }^{24}$ quiere ejemplificar la ambivalencia y complejidad de de protección humanitaria internacional a través de la trilogía de Las Danaides de Esqui$10^{25}$. Efectivamente, las hijas de Dánao huyen y obtienen asilo en Argos, por temor al matrimonio forzoso al que quieren someterlas los hijos de Egipto. Trasladada la tragedia griega a nuestros días, nos encontraríamos ante un caso que sería considerado como una persecución privada, de manera que, probablemente, a las Danaides les sería denegada la condición de refugiadas y, por ello, la protección de la Convención de Ginebra. Asimismo, tampoco quedarían dentro del amparo de la Protección Subsidiaria. Estariamos, en el mejor de los casos, ante un hipotético supuesto de protección por razones meramente humanitarias, que quedaria a la libre discreción del Estado de recepción sin protección internacional alguna.

\section{Migraciones forzosa, nuevos refugiados $y$ derechos humanos}

La posición de los Estados ante las migraciones forzosas y la protección de los nuevos refugiados implica necesariamente una toma de postura coherente ante la diversidad cultural, característica propia de la sociedad globalizada en la que vivimos. Cualquier reflexión sobre la convivencia entre distintas culturas trae de la mano el debate sobre el origen de los derechos humanos fundamentales y de su carácter universal, inderogable e indivisible.

Hemos de comenzar distinguiendo un núcleo duro de derechos humanos universales que tiene su fundamento en el concepto de la dignidad de la persona humana y que todos debemos respetar y hacer respetar. La trasgresión de éstos por una parte importante de Estados miembros de la comunidad internacional provoca la existencia de refugiados según la Convención de Ginebra y una buena parte de los denominados nuevos refugiados.

El Derecho Internacional de los Derechos Humanos es una de las ramas más jóvenes del Derecho Internacional Público. El llamado núcleo duro de los derechos humanos fundamentales queda compilado en el artículo 3 común a las Convenciones de Ginebra sobre Derecho Humanitario Bélico de 1949. Los derechos enunciados en dicho artículo 3 son los siguientes: el derecho a no ser privado arbitrariamente de la vida, el derecho a la integridad física y moral, el derecho a no sufrir tortura ni tratos crueles inhumanos o degradantes, el derecho a no sufrir esclavitud, el derecho a no ser castigado por actos que en el momento de su comisión no fueran constitutivos de delito y el derecho a la tutela judicial efectiva en la protección de dichos derechos básicos. Este mínimo, como vemos, deja abierto un debate sobre el derecho a la vida en relación con la legitimidad de la condena a la

ARBOR CLXXXI 713 MAYO-JUNIO [2005] 133-142 ISSN: 0210-1963 
pena de muerte, dicho debate sólo en Europa se ha cerrado ya de manera decidida a favor de la teoría abolicionista 26 .

Por otra parte, el artículo 3 citado, común a las convenciones ginebrinas, parte de la distinción entre derechos humanos y derechos humanos fundamentales: es decir mientras que derechos humanos son todos los relativos al hombre, sólo algunos son, además, derechos humanos fundamentales. Es importante distinguir ese "núcleo duro» de los derechos humanos, aquellos de los que predicamos su ámbito universal 27 .

La reflexión podria terminar aqui si el género humano compartiera el mismo concepto de dignidad. No obstante, existen posturas discrepantes $y$, por ello, en ocasiones diferimos en la identificación de las víctimas. El problema sobreviene, por ejemplo, cuando las mismas personas que nosotros (ciudadanos pertenecientes a las sociedades basadas en el respeto a los derechos humanos fundamentales y en los regimenes democráticos de convivencia) consideramos víctimas de violaciones severas a sus propios derechos fundamentales, no son vistas como tales en sus sociedades de origen ${ }^{28}$.

Así, nuestra profunda convicción de que el fundamento de los derechos humanos de ámbito universal arranca del concepto de dignidad de toda persona ${ }^{29}$, puede resultar un argumento no del todo convincente para quienes parten de aproximaciones distintas y afirman que pueden existir tantas maneras de entender los derechos humanos como civilizaciones o culturas. Aún cuando, ante dicha posición, siempre queda que las soberanias estatales prohiban ciertas prácticas e impongan límites al relativismo cultural, sin embargo, la gran batalla, esto es, la del entendimiento univoco de los derechos fundamentales, no quedaria para todos pacíficamente resuelta.
La multiculturalidad es un elemento estructural de la sociedad internacional globalizada, una realidad tan inevitable como enriquecedora. Quiero traer aqui la reflexión de realiza Velasco $(2002,279)$ a propósito de una conocida obra de Sartori 30 :

\section{"Si por multiculturalismo entendemos como sostiene Sartori, que bajo una misma frontera convivan cultu- ras distintas gobernadas por leyes propias y diferentes, no cabe duda de que estaríamos ante una doctrina "negativa y disgregadora» (...). Si, por el contrario, bajo dicho término se entiende que cada persona pueda expresar su cultura y conformar su propia identidad dentro de la ley del país receptor estariamos ante un ejercicio de libertad dificilmente criticable».}

Las generaciones del presente siglo nos enfrentamos a enemigos cuyas artimañas y astucias nos son poco conocidas. Ello nos causa temor y desasosiego. La conmoción mundial por los atentados del 11 de septiembre de 2001 y del 11 de marzo de 2004 no sólo nos encogió el alma, sino también nos obliga a prepararnos para una batalla difícil que requiere de la reflexión y la cooperación de todos.

Sin embargo, hemos de tener cuidado de no responder con fanatismo al fanatismo. El respeto a la dignidad humana, la libertad, la democracia, la igualdad, el Estado de Derecho, los derechos humanos, el pluralismo, la no discriminación, la tolerancia, la justicia y la solidaridad ${ }^{31}$, han de ser los valores que nos guien en la complicada tarea de preservar o restablecer la paz y seguridad mundial. Otras lecturas pueden conducirnos a conclusiones sobre la relación entre multiculturalidad y convivencia pacífica como la siguiente: "a menos que odiemos lo que no somos, no podremos amar lo que somos» ${ }^{32}$. Afirmación que considero tan errada como inicua. 
1 La Ayuda Oficial al Desarrollo anual por parte de los paises desarrollados en 2002 consistió en unos 58.000 millones de dólares y el beneficio que los paises pobres obtendrian si los paises ricos liberalizaran el comercio sería de más de 124.000 millones de dólares, es decir, más del doble de la cuantía de la ayuda citada. Id.

2 Para un breve exposición y revisión de las diferentes teorias económicas de las migraciones y de los push y pull factors de éstas desde el punto de vista económico, vid, Argerey, 2005, 102-132.

3 Para De Lucas hay que superar en el debate sobre la inmigración tanto la visión instrumental que relaciona la inmigración con el mercado o la seguridad, como la meramente humanitaria "anclada en la conmiseración o la piedadn. En cuanto a la instrumentalización de la inmigración con el mercado, constituye un buen botón de muestra el acceso del inmigrante a la sanidad, parece que la cuestión está en saber "cuales son los costes de mantenimiento asumibles para mantener los beneficios que nos proporcionan (estaría uno tentado de decir los costes de atención veterinaria, es decir, los que se prestan a un instrumento o animal para que funcione)m, DE LUCAS, 2002,59 y 63.

4 Las respuestas de las sociedades de acogida en cuanto a los modelos de integración a aplicar son diversas. De entre ellas, la multiculturalista -aunque tanto se tergiverse en los tiempos que corren- es la más respetuosa con la defensa de los derechos humanos universales. Quede bien establecido, que el modelo multiculturalista, al menos en el entendimiento que de él tiene esta autora, en modo alguno supone contemporizar con la barbarie. En Europa se han adoptado distintos modelos respecto a la integración de los inmigrantes. Francia es el ejemplo por antonomasia del modelo asimilacionista; Alemania ha seguido el llamado modelo de trabajadores invitados y el Reino Unido ha optado hasta hace poco por el modelo multicultural. Tras los atentados del 11 de septiembre de 2001, se produce un punto de inflexión y el Reino Unido parece decantarse por abandonar el modelo multiculturalista y acercarse al modelo asimilacionista. Vid, REX, 2002, 33 y 42.
5 La Directiva europea 2003/86 sobre Reagrupación familiar de los nacionales de terceros paises (Doce 2003 L251/12) ha sido objeto de un recurso judicial presentado por el propio Parlamento Europeo ante el Tribunal de Justicia de la Unión Europea. Dicha Directiva, cuyo periodo de transposición terminaria en octubre de 2005 , permite que los Estados miembros supediten el derecho del inmigrante a la reagrupación familiar con sus hijos entre 14 y 18 años, a que éstos cumplan con determinados requisitos de aptitud para la integración. Algunos hemos encontrado esta disposición claramente contraria al Convenio de Naciones Unidas sobre los Derechos del Niño (vinculante para todos los miembros de las Naciones Unidas excepto Estados Unidos y Somalia) y esperamos, con cierta ansiedad, el fallo del Tribunal de Justicia de la UE. (Gortázar., 2003, 226)

6 Vattel distingue en su Derecho de Gentes claramente a los emigrados "Lámanse emigrados los que abandonan su Patria por alguna razón legítima, con el designio de establecerse en otra parte, y se llevan consigo sus bienes y sus familias" (CCXXIII, Tomo I), de los suplicantes "Se llaman suplicantes aquellos fugitivos que imploran la protección de un soberano contra la nación ó el Príncipe que abandonaron (...)». (CCXXVI, Tomo I) y de los desterrados "un desterrado es un hombre alejado del lugar de su domicilio ú obligado á salir de él sin otra infamia" (CCXXVII). Aunque la breve andadura del Derecho internacional de la época sólo le permite establecer que respecto de los suplicantes el derecho de gentes no puede decidir "solidamente" sin tener en cuanta las relaciones de una nación hacia las demás, con relación a los desterrados y extrañados dispone: "Los desterrados y extrañados tiene derecho á vivir en alguna parte. Un hombre porque se le destierre ó se le extrañe $n$ opierde su cualidad de hombre, ni por consiguiente el derecho áhabitar en alguna parte de la tierra; pues tiene este derecho de la naturaleza ó mas bien de su autor que destinó la tierra á los hombres para su habitación; $y$ la propiedad no ha podido introducirse en perjuicio del derecho que todo hombre trae consigo al nacer para usar de las cosas absolutamente necesariasi
(CCXXVIII, Tomo I). VATTEL, 1820, 293, 296 y 298 . Nótese que se mantiene la ortográfia original.

7 En adelante, Convención de Ginebra.

8 Fernández Sánchez (Coord.), 2002.

9 I.e.: Convención de Addis Abeba de 1969 en el ámbito africano o Declaración de Cartagena de 1982 en el ámbito iberoamericano. Sobre estos textos de ámbito regional, volveremos infra nota 18 . Recientemente, en la Unión Europea, se ha acuñado el término Protección Subsidairia en la Directiva europea 2004/83 (Doce 2004 L 304/12.

10 Salvadas las restricciones que eliminó el Protocolo Adicional a la Convención de Ginebra, firmado en Nueva York en 1967.

11 Constituyen causas de exclusión: haber cometido crimenes de guerra o genocidio, actos contrarios a los principios y propósitos de la Carta de las NU o un grave delito común fuera del país de refugio. Las causas de cesación están en relación con el cambio de circunstancias en el pais de origen el cual deja de ser una amenaza para el refugiado.

12 "The Queen v. The Secretary of the State for the Home Department (Ex parte Adan \&t others) Cámara de los Lores, 19 de diciembre de 2000. En dicho asunto, una somali, un argelino y un sri lankés, que habian pasado por Francia - uno de elloso pedido asilo en Alemania -los otros dossolicitan protección en el Reino Unido por considerar que Francia y Alemania no les protegen contra la devolución al pais de persecución ya que interpretan la Convención de Ginebra excluyendo la persecución cuando ésta proviene de agentes no estatales. La Corte de Apelación inglesa entiende que, efectivamente, Francia y Alemania no son paises seguros ya que no realizan una interpretación "adecuada" de la Convención de Ginebra al excluir la protección proveniente de agentes no estatales y que, por dicho motivo, no procede aplicar el Convenio de Dublin sobre el reparto de responsabilidad en el examen de las solicitudes de asilo presentadas en los Estados miembros de la Unión Europea. Asi lo confirma la Cámara de los Lores. Vid. Goodwin-Gill(1999, 730-737); 
13 La Convención de la Organización para la Unidad Africana (OUA) sobre Aspectos Específicos de los Problemas de los Refugiados en Africa, firmada en Addis-Abeba en 1969, además de recoger los criterios que definen al refugiado en la Convención de Ginebra de 1951,añade: "El termino refugiado deberá aplicarse también a toda persona que, por causa de agresión extranjera, ocupación, dominación extranjera o hechos que perjudiquen gravemente el orden público, tanto en una parte como en la totalidad de su pais de origen o nacionalidad, se viera obligada a dejar su lugar de residencia habitual, para buscar refugio en otro lugar fuera de su país de origen o nacionalidad». En el ámbito iberoamericano, la definición de refugiado es adoptada en el seno de la Organización de Estados Americanos, en 1984, en la llamada "Declaración de Cartagena». Además de los refugiados descritos en la Convención de Ginebra, la Declaración incluye a: "(...)las personas que han huido de sus paises porque sus vidas, su seguridad o su libertad han sido amenazadas por la violencia generalizada, la agresión extranjera, los conflictos internos, la violación masiva de los derechos humanos u otras circunstancias que hayan perturbado gravemente el orden públicon.

14 Se trata de una protección "de rebote" (protection par ricochet).

15 Directiva de 29 de abril de 2004. L 304/23. Doce 30 de septiembre de 2004. En adelante, Directiva sobre interpretación del Estatuto de Refugiado y sobre Protección Subsidiaria.

16 En virtud de los Protocolos sobre la posición del Reino Unido e Irlanda, por u.na parte, y sobre la posición de Dinamarca, por otra, anejos al Tratado de la Unión Europea y al Tratado constitutivo de la Comunidad Europea. El Reino Unido notificó su opting in por carta de 28 de enero de 2002 e Irlanda por carta de 13 de febrero de 2002.

17 Artículo 1(a) 2 de la Convención de Ginebra.

18 Artículo 15 de la Directiva sobre interpretación del Estatuto de Refugiado y sobre Protección Subsidiaria.
19 lbid., artículo 6.

20 lbid., artículo 9.

$21 \mathrm{lbid}$, artículo 10.

22 Quienes hemos seguido las distintas versiones de la presente Directiva recordamos cómo el Proyecto de Directiva en su versión anterior recogía en su artículo 12 sobre motivos de persecución: "el concepto de grupo social incluirá un grupo que pueda definirse en función de ciertas características fundamentales, como la orientación sexual, edad y sexo (...)m. En la Exposición de Motivos se mencionaba que la "pertenencia a determinado grupo social" podia incluir a "mujeres víctimas de violencia doméstica, incluidas la violencia sexual y las mutilaciones, en aqueIlos Estados donde no pueden obtener protección efectiva contra tal abuso por su sexo o situación social como mujeres casadas, hijas, viudas o hermanas, en esa sociedad particularn.

23 En cuanto al Tratado por el que se establece una Constitución para Europa de 29 de octubre de 2004, actualmente en periodo de ratificación, conviene tener presente que el artículo II-78 (de la Parte Segunda, la cual incorpora la Carta de Derechos Fundamentales de la Unión Europea) garantiza el derecho de asilo en el respeto a la Convención de Ginebra. Asimismo, el artículo $11-79$ recoge que nadie podrá ser devuelto, expulsado o extraditado a un Estado en el que corra un grave riesgo de ser sometido a pena de muerte, tortura o penas o tratos inhumanos o degradantes. En cuanto a las Politicas de inmigración y Asilo, el artículo III-265 y siguientes, junto a las medidas para el control de la frontera externa y la garantía de ausencia de control en las fronteras internas, establece que una ley o ley marco tomará las medidas para un Sistema Europeo Común de Asilo (SECA) esto es, un estatuto uniforme de asilo válido para toda la Unión. Dicho estatuto uniforme alcanza también a los supuestos de Protección Subsidiaria.
24 Los hijos de Egipto acabarian, no obstante, por raptar a las Danaides y llevar a cabo su matrimonio forzoso con éstas. Las hijas de Dánao, en venganza, matarian a sus respectivos maridos durante la noche de bodas excepto Hipermestra quien, seducida, amaria a su esposo Linceo por haberla respetado...Según uno de los mitos sobre el nacimiento de Europa, ésta sería hija de dicho amor... ¿Cabría decir que Europa sobrevive a la violación del derecho de asilo? ( Carlier, 2004, 1)

25 Como es sabido, de la triologia formada por Suplicantes, Egipcios y Danaides, solo se conserva la primera pieza.

26 El 1 de julio de 2003 entraba en vigor el Protocolo número 13 al Convenio Europeo de Derechos Humanos por el que se rechaza, sin posibilidad de excepción o derogación, la pena capital en el seno del Consejo de Europa. En el ámbito de Naciones Unidas - véanse los convenios sobre Derecho Humanitario Bélico citados- no hay aún consenso en cuanto a la condena de la pena de muerte, por ello, el artículo 3 común a los Convenios de Ginebra sobre Derecho Humanitario Bélico sólo enuncian entre los derechos a proteger el de "no ser privado arbitrariamente de la vidan.

27 La Comisión Europea de Derechos Humanos decidió, por ejemplo, que el derecho de un militar escocés a llevar el cabello largo -algo prohibido por la legislación militar escocesa-, no constituia un derecho fundamental que la Corte de Estrasburgo debiera imponer a la legislación del Estado Parte. No obstante, en el asunto de Soering v. Reino Unido, la misma Corte Europea entendió que el derecho de Soering a no sufrir el pasillo de la muerte previo a la pena capital -en caso de ser extraditado al estado de Virginia donde estaba perseguido como presunto asesino de los padres de su novia- constituia un derecho humano fundamental inderogable. 


\section{BIBLIOGRAFÍA}

28 Hace algún tiempo escuchaba a una somali, licenciada en Derecho por una prestigiosa universidad europea, rechazar los motivos por los que en Occidente condenamos sin fisuras la práctica de la ablación femenina. En su opinión, la razón esgrimida, esto es, que dicha práctica vulnera la dignidad de la mujer, no era en absoluto aceptable por cuanto, precisamente, la dignidad es el fundamento que mueve a una buena madre somali a circuncidar a su joven hija, la cual sólo asi recibiría el respeto y la aceptación social: por fin, evitar la circuncisión constituiria un atentado contra su propia dignidad como mujer (Gortázar, 2004, 108).

29 Y que dicho concepto no es sólo occidental sino que, independientemente de cuál haya sido su cuna, abarca a la humanidad entera, ya que deriva de la ley natural que lo presenta desvestido de todo vestigio religioso o cultural.

30 Sartori (2001 y 2002).

31 Valores recogidos todos ellos en el Artículo Primero del Tratado por el que se establece una Constitución para Europa.

32 Expresión citada por Huntington $(1997,20)$. Dykinson. Zaragoza, Egido.
Aparicio, R. y Tornos, A. (2000): La Inmigración y la Economía española. Madrid. Instituto Universitario de Estudios sobre Migraciones, Universidad P. Comillas. Imserso, Ministerio de Trabajo y Asuntos Sociales.

Argerey, P. (Coord.) (2005): El Fenómeno de la Inmigración en Europa: Perspectivas Jurídicas y Económicas. Madrid,

Carlier. J-Y. (2004) : «Le développement d,une politique commune en matière d,asilem. Dias Urbano De Sousa, C y De Bruycker, P. (Coord.) The Emergence of a European Asylum Policy. Bruselas, Bruylant.

Chueca Sancho, A. G. (1998): La expulsión de extranjeros en la Convención Europea de los Derechos Humanos.

De Lucas, J. (2002): "La herida original de las politicas de inmigración", en Isegoría, no 26, pp. 59-84.

Esquilo (1993): Tragedias Completas, Madrid. ed. de Alsina Clota, Cátedra.

Fernández Sánchez, P. A. (Coord.) (2002): La revitalización de la protección de los refugiados. Huelva. Universidad de Huelva.

Goodwin-Gill, G. (1999): The margin of interpretation: different or disparate? International Journal of Refugee Law. Vol 11, núm.4.

Gorgátar C. J. (2005): "La inmigración: ¿un problema o una fuente de riqueza?». (Campoy, l; Rey, J. L.; Rodríguez Palop, M. E. Coords.) Desafios actuales a los derechos humanos: violencia doméstica, inmigración y medios de comunicación. Universidades Comillas de Madrid y Carlos III de Madrid. Madrid. Dykinson (en prensa).

Gortázar C. J. (2003): «Familia y Cultura. La Familia Inmigrante en la normativa de la UE" Borobio, D. (Coord.). Familia e Interculturalidad. Salamanca. Universidad Pontificia de Salamanca, Estudios Familiares no 13.
Gortázar, C. J. (2002): Two Inmigration Acts at the End of the Millenium. European Journal of Migration and law. Kluwer Law International. Vol 4, no 1.

Gortázar C. J. (2004): El Bien común internacional: la Familia Humana y Los Derechos Humanos Fundamentales de Ámbito Universal. Madrid. Cuadernos, Instituto Social León XIII. № 3.

Huntington, S. P. (1997): El Choque de civilizaciones y la reconfiguración del orden mundial. Barcelona. Paidós.

Lamo De Espinosa, E. (2004): Bajo puertas de fuego, el nuevo desorden internacional. Madrid. Taurus.

Merle, J-C. (2002): "Liberalismo y derecho a la inmigración. Sobre una concepción y un dilema de la teoría liberal contemporánea", en Isegoría, $n^{\circ} 26$, pp. 45-57.

Rex, J. (2002): "Multiculturalismo e integración política en el Estado nacional modernow en Isegoría, $n^{\circ} 26$, pp. 29-43.

Sartori, G. (2001): La Sociedad Multiétnica. Pluralismo, Multiculturalismo y Extranjeros, Madrid, Taurus.

(2002): La Sociedad Multiétnica. Extranjeros e Islámicos (Apéndice actualizado), Madrid, Taurus.

Vattel El Derecho de Gentes. Trad. Manuel Pascual Hernández (1820). Madrid. Imprenta de I. Sancha.

Velasco, J. C. (2002): "Los límites del pluralismo cultural: ¿Stop a la inmigración musulmana?», en Isegoría $n^{\circ} 26$, pp. 277-284. 